\title{
Climate change and respiratory disease: European Respiratory Society position statement
}

\author{
J.G. Ayres, B. Forsberg, I. Annesi-Maesano, R. Dey, K.L. Ebi, P.J. Helms, \\ M. Medina-Ramón, M. Windt and F. Forastiere, on behalf of the Environment and \\ Health Committee of the European Respiratory Society ${ }^{\#}$
}

ABSTRACT: Climate change will affect individuals with pre-existing respiratory disease, but the extent of the effect remains unclear.

The present position statement was developed on behalf of the European Respiratory Society in order to identify areas of concern arising from climate change for individuals with respiratory disease, healthcare workers in the respiratory sector and policy makers. The statement was developed following a 2-day workshop held in Leuven (Belgium) in March 2008.

Key areas of concern for the respiratory community arising from climate change are discussed and recommendations made to address gaps in knowledge. The most important recommendation was the development of more accurate predictive models for predicting the impact of climate change on respiratory health.

Respiratory healthcare workers also have an advocatory role in persuading governments and the European Union to maintain awareness and appropriate actions with respect to climate change, and these areas are also discussed in the position statement.

\section{KEYWORDS: Advocacy, climate change, respiratory disease}

$\mathrm{t}$ is now widely accepted that climate change is occurring as a result of anthropogenic factors, in particular, fossil fuel combustion and greenhouse gas (GHG) emissions from energy supply, transport, agriculture, industry, forestry, waste, and commercial and residential buildings. Although global approaches are required in order to mitigate the increase in global temperatures, climate change is likely to have many, mostly adverse, effects on health, particularly in low-income countries, which require attention and action. These findings have been well described by the Intergovernmental Panel on Climate Change (IPCC) [1] and the World Health Organization (WHO) [2].

Climate change, and its driver GHG emissions, will thus affect human health [1] and respiratory medicine through: 1) an increased number of deaths and acute morbidity due to heatwaves; 2) an increased frequency of cardiorespiratory events due to higher concentrations of groundlevel ozone; 3) changes in the frequency of respiratory diseases due to transboundary longrange air pollution (e.g. related to fires and aerosols); and 4) altered spatial and temporal distribution of allergens and some infectious disease vectors. These impacts will not only affect those with existing respiratory disease but also may influence the incidence and thus prevalence of respiratory conditions.

The impact of climate change on individuals with respiratory disease will vary depending on the degree to which ambient temperatures rise relative to current levels, changes in short-term transboundary long-range air pollutants, the risk of heatwaves, and the risk of flooding and excessive rainfall, as well as the impact of these changes on other health-relevant factors, such as air pollution, allergens and moulds. Adaptive capacity must be expanded beyond simply responding to extreme events as planning for the longer term is needed. Consequently, diagnostic tools and clinical treatments may need to be adjusted with time and clinicians will need to

\section{AFFILIATIONS}

For affiliations, please see the Acknowledgements section, and \#For members of the Environment and Health Committee of the European Respiratory Society, please see the Acknowledgements section.

CORRESPONDENCE

J.G. Ayres

Institute of Occupational \& Environmental Medicine University of Birmingham Birmingham B15 2TT UK E-mail: j.g.ayres@bham.ac.uk

Received:

Jan 082009

Accepted after revision:

Feb 192009 
be made aware of changing patterns of disease that will occur in response to changing environmental conditions. This requires better disease surveillance and warning systems.

The Environment and Health committee of the European Respiratory Society (ERS) held a workshop in Leuven (Belgium) in March 2008 in order to explore the specific health issues of climate change in relation to respiratory disease. The present position statement has arisen from that workshop. Although climate change and health have been addressed in the general medical literature $[3,4]$, this statement is the first from a specialist medical society and parallels the interest of the American Thoracic Society in climate change [5]. The statement highlights the broad issues facing the medical profession, those pertinent to respiratory disease, how approaches to the likely change in pattern of disease can be managed, gaps in knowledge and how all of this can be used in advocacy, in particular to governments. The statement reflects the Environment and Health Committee's role in advising both the ERS and the European Lung Foundation on matters of environment and health, and providing information to these and other relevant bodies, as well as the general public.

Within this statement two main themes have been addressed: 1) adaptation: actions designed to reduce the impact of already established climate change on patients with respiratory disease and to protect the public from related exposures known to adversely affect lung health; and 2) mitigation: responsibilities of healthcare professionals and organisations, such as the ERS, to lead by example in reducing dependence on carbon and hence contributing to reducing the influence of climate change and its impact on future generations.

\section{CLIMATE CHANGE}

Global temperature has risen markedly since the late 1970s due to increases in GHG emissions, largely from anthropogenic sources [1]. For example, mean annual central England temperatures have continued to rise and are now $>2{ }^{\circ} \mathrm{C}$ higher than in the coldest period of the Little Ice Age in the late seventeenth century, with half of this increase occurring since the late 1960s [6]. This increase in temperature has also seen a rapid rise in the number of hot days and severe meteorological events, such as the 2003 heatwave, during which temperatures of $\geqslant 35^{\circ} \mathrm{C}$ were reached [6], resulting in $\sim 40,000$ excess deaths across Europe. Sea levels have also started to rise as a consequence, with clear regression of the polar ice packs. This combination has led to water deprivation in certain areas, often associated with water degradation, which could potentially result in population migration and the effects on health that result from mass population movement. Changes in biodiversity, land use, crop yields and soil degradation could lead to problems with malnutrition through reduced food availability, thus potentially increasing the incidence of respiratory infections.

The key determinants of GHG emissions are energy production, consumption and efficiency, transport, agriculture and food production, and waste management [7], and attempts at mitigating climate change will need to address each of these. However, it is likely that the world will experience more hot days, fewer frost days, and more periods of heavy rain and consequent flooding [1]. Paradoxically, it is likely that there will be more periods of drought [1].

\section{CLIMATE CHANGE AND RESPIRATORY DISEASE}

The key climatic change factors that could potentially influence respiratory disease are extreme temperature events (both hot and cold), changes in air pollution, flooding, damp housing, thunderstorms, changes in allergen disposition and consequent allergies, forest fires and dust storms, the effects either being short or long term.

The main disease areas of concern are asthma, rhinosinusitis, chronic obstructive pulmonary disease (COPD) and respiratory tract infections, but the extent to which these will be impacted will vary according to the proportion of susceptible individuals in a given population. Areas of greater poverty with limited access to medical services will suffer more, as will those areas with less-well-developed medical services, which will include migrating populations and areas where population growth is greatest.

\section{Extreme temperature events}

In Europe, an increase in the frequency and intensity of summer heatwaves is expected, especially in central, eastern and southern countries [1]. These changes will contribute to the burden of diseases and premature deaths, particularly in population subgroups with limited adaptive capacity, such as the elderly and patients with COPD. In the summer of 2003 in Italy, those aged $>65$ yrs experienced a $34 \%$ greater risk of dying during hot days, with higher risks for respiratory disease [8], although effects vary between heatwaves [9]. Heatrelated mortality is higher in females [8] and COPD patients in a hospital without appropriate climate control at the time of the heatwave [10]. In a multi-city European study, the estimated overall change in all-cause mortality for a $1^{\circ} \mathrm{C}$ increase in maximum apparent temperature above the cityspecific threshold was $3.1 \%$ in the Mediterranean region and $1.8 \%$ in the north-continental region, with a greater effect on respiratory mortality (6.7 and 6.1\%, respectively) [10], advancing the date of death by months. Hospital admissions for respiratory diseases follow the same pattern, especially in the very elderly [11].

In addition, there will be a reduction in the number of cold spells, which may result in a fall in winter respiratory deaths, especially in the more northerly countries.

\section{Adaptation}

Such increased exposure to heat could be reduced by modifications to indoor living, such as changes in building design, particularly for the susceptible elderly, for both personal and communal housing. Although increased use of air-conditioning can be considered (where feasible), this is a significant contributor to global warming and alternative approaches to cooling indoor spaces are required. Behavioural change will be critical as people learn the appropriate response to a period of high temperature. The WHO Regional Office for Europe [2] has prepared a list of short- and long-term measures for dealing with the health effects of heatwaves. Reducing air pollution during heatwaves will be critical to the success of preparedness for heatwaves. Respiratory physicians should pay attention to vulnerable patients, perform pre-summer medical assessments and advise on routine care, including fluid intake and adjustment of medications during hot weather. 


\section{Air pollution}

Ozone

The concentration of air pollutants in the atmosphere is highly dependent upon the weather, particularly for those pollutants that result from photochemical reactions, e.g. tropospheric ozone [12], itself a potent GHG. Climate change is expected to alter the concentration and distribution of pollutants in the atmosphere, but the magnitude and direction of the change is unclear [13]. Most projections have focused on ozone levels and, assuming that precursor emissions will remain constant, they predict an overall increase in ozone concentrations in high-income countries, but with wide regional differences [14]. This could have important health consequences, especially for those suffering from chronic respiratory diseases. Ozone is a powerful oxidant that has been associated with reduced lung function [15], exacerbation of chronic respiratory diseases [16], and increases in respiratory hospital admissions [17, 18] and mortality $[19,20]$ in both Europe and the USA. It has been estimated that, in the UK, there will be 1,500 more ozoneassociated deaths annually by the year 2020 [21].

\section{Particles}

The impact of climate change on ambient particle concentrations is uncertain [14]. Although mitigation policies may result in reductions in particle emissions at the local level, desertification and a higher frequency of forest fires may increase transboundary transport of particles [13, 22]. Long-term exposure to particles has been associated with increased symptoms and reduced lung function in asthmatic children [23] and higher mortality in adults, including lung cancer deaths [24-26]. Similarly, short-term increases in ambient particle levels have been related to increases in cardiopulmonary hospital admissions and mortality [27-29]. If significant increases in particle levels are seen with climate change, it could thus have significant public health consequences.

\section{Synergy between air pollution and temperature}

Even with stable levels of ozone and particles, climate change may enhance the adverse effects of these pollutants because of warmer conditions. Adverse effects of ozone have been observed specifically during the warm season [19, 30, 31], with some evidence of a synergistic effect between high temperature and ozone $[32,33]$. Similarly, larger particle effects during the summer and/or the presence of a synergistic effect between particles and temperature have been reported [31,34], although the possibility of reduced exposure to outdoor air pollutants in winter months has not been investigated. Recent experimental work confirms that the redox activity of particles is amplified by ozone [35], raising the possibility of a three-way interaction between particles, ozone and temperature in the future.

\section{Adaptation}

Actions taken towards adaptation to climate change should be aimed at reducing emissions and instituting means of coping with higher temperatures. These may involve changes in activity patterns that could ultimately affect human exposure to air pollution (e.g. minimising time spent outdoors to avoid heat). Conversely, some strategies may lead to higher air pollution levels, for instance growth in energy demand due to increased use of air-conditioning during the summer. Similarly, a switch from petrol to diesel cars, potentially more energy efficient, could result in additional exposure to diesel particles. Thus climate change mitigation and adaptation strategies need to be carefully evaluated with regard to their impact on air quality.

\section{Effects of flooding and damp}

It is likely that climate change will be associated with more episodes of extreme precipitation [1], potentially leading to severe flooding, consequent population dislocation, poor living conditions and worsening water quality, poor nutrition and inadequate access to medical care. This will affect respiratory infections, pneumonia in particular.

Lesser degrees of flooding will also lead to housing remaining habitable but being damp. Damp housing has long been recognised as a cause of respiratory ill-health [36-38], being consistently associated with cough and wheeze (and to a lesser extent asthma) in both children and adults. In the USA, damp and mould exposure have been estimated to contribute to approximately a fifth of all cases of asthma, potentially with a high economic impact [39]. Although a role for allergic sensitisation associated with fungal exposure is plausible [40], the evidence is less strong and the reasons for damp affecting respiratory symptoms are unclear as most studies have been cross-sectional in nature, few having used objective measures of exposure. Changes in indoor conditions with climate change may permit house dust mites to become established in regions in which cold winters and heating have previously prevented colonisation [41].

The potential for exposure to other bioactive molecules associated with damp housing, such as endotoxins, volatile organic compounds and mycotoxins, may also be relevant.

\section{Adaptation}

There is some evidence to suggest that better-insulated homes improve indoor temperatures and are associated with improved markers of health $[42,43]$, and there is some evidence that house dust mite populations can be controlled by improved house design incorporating environmental control.

\section{Effects on allergens and allergic responses}

Increased temperatures in more northerly latitudes will permit the spread of certain plant species to larger areas, thus exposing new populations to, for them, novel allergens [44], and levels of recognised outdoor moulds (Alternaria and Cladosporium) may also increase. To what extent this will result in more individuals with respiratory allergies is conjectural, but any increase in allergen load in conjunction with rising ozone levels will result in more exacerbations of asthma and allergic rhinitis as ozone potentiates the effects of allergen exposure [45], and exposure to higher concentrations of dust mite allergen in households is associated with an increased incidence of asthma. It is likely that, with climate change, there will be an increase in thunderstorms, which are known to be associated with outbreaks of asthma mediated through allergen exposure, notably pollens and wet-air fungal spora [46-50].

\section{Adaptation}

Owing to the uncertainty as to the extent of changes in pollen distribution and consequent allergen sensitisation with climate change, specific adaptations cannot be recommended other 
than to limit exposure through avoidance and to press for prospective collection of data relevant to this phenomenon through collaborative research.

\section{Effects of indoor air pollution}

Indoor air pollution from the burning of solid fuels, largely from biomass for cooking and heating, is the fourth leading cause of morbidity and mortality in the developing world, particularly due to acute respiratory infection in children aged $<5$ yrs (with an estimated 1.5 million deaths $\cdot \mathrm{yr}^{-1}$ ) [51] and COPD in nonsmoking females. Recent scientific data indicate that black carbon (soot) from indoor air pollution is the second leading air emission contributing to the greenhouse effect and global warming [52]. Black carbon has a half-life in the atmosphere of weeks as opposed to hundreds of years for carbon dioxide, and so interventions targeting a reduction in biomass emissions may be of benefit within the foreseeable future.

\section{Adaptation}

Adaptation must be considered on a country-by-country basis but should aim to reduce indoor air pollution by introducing more efficient cooking stoves that reduce both emissions (combustion efficiency) and fuel use (fuel efficiency). The latter also has major benefits for the environment by reducing the impact of deforestation from unregulated felling of trees for fuel, which contributes to soil erosion and the loss of an important natural source of $\mathrm{CO}_{2}$ sequestration.

\section{Changes in respiratory infections}

It is likely that climate change will alter the frequency of some infections, in particular, tuberculosis and respiratory syncytial virus. The timing and duration of the respiratory syncytial virus season has changed since the mid-1990s, the season ending earlier as temperatures have increased, attacks also being less severe. Tuberculosis may increase in some circumstances, especially with migrating populations potentially finding themselves in situations associated with more crowding [53].

The effect of seasonality will probably also impact beneficially on other respiratory infections due to warmer winters. The seasonality of respiratory infections is poorly understood, although temperature is thought to play an important part, along with patterns of transmissibility due to population behaviour, such as spending more time outdoors in the milder winters. In general, respiratory infections increase during winter months [54] and so warmer winters may well reduce their frequency. It is possible that some respiratory infections currently limited geographically may increase in range. Chikungunya virus infection had been identified to date only in tropical areas, but recent outbreaks in Italy could have been influenced by higher temperatures, permitting the vector (Aedes albopictus) to thrive [55], although provision of environmental niches, notably water pools in rubber tyres, trade in which has increased globally, may also contribute. Climate change might affect the ecology of avian influenza viruses through alteration of bird migration, and influence on the avian influenza virus transmission cycle and virus survival outside the host. The joint net effects of these changes are rather unpredictable, but it is likely that avian influenza virus circulation in water bird populations will continue with persistent adaptation and evolution [56].

Consequently, the overall effect of climate change on respiratory infections is likely to be modest and may even be beneficial. However, as increases in air pollution will occur, increasing susceptibility to infections may result.

\section{GAPS IN KNOWLEDGE AND RECOMMENDATIONS FOR RESEARCH}

Knowledge in the area of climate change and respiratory heath is based on limited information and substantial-but-informed speculation. There are many gaps in this knowledge, many of which will only truly become clear as climate change advances, which may be too late for some situations. Consequently, much research is needed into the improvement of predictive models supplemented by continuous prospective measurement and assessment of the key outcomes and exposures which determine the impact of climate change on respiratory health. The complexity of the issues involved requires coordination and collaboration across research disciplines.

\section{Increased understanding of the current and projected impacts of climate change on respiratory health}

1) There is limited information regarding how changes in temperature, precipitation and other weather variables might affect the geographic range and incidence of mortality and morbidity from respiratory diseases. Examples are as follows. 1) Formation of ground-level ozone is for the most part temperature-dependent and so, although there is not always a clear positive association, if precursor emissions are not reduced, increasing temperatures will increase ozone concentrations, which would adversely affect susceptible groups (particularly children, the elderly, and people with asthma and COPD). It is not known to what extent this will occur. 2) Plants are flowering earlier in the spring, lengthening the allergy season. There is limited evidence that increased temperatures and $\mathrm{CO}_{2}$ concentrations could increase pollen allergenicity. Systems need to be put in place to monitor changes in aeroallergen concentrations and how they might match to changes in sensitisation. 3) Increasing heavy precipitation events, with subsequent flooding, could increase exposure to indoor damp and moulds.

2) Effective research requires development of long-term data sets on the incidence and prevalence of respiratory diseases, as well as of the environmental and social factors with which they are associated. This will require construction of data sets that are spatially linked at a suitable level of resolution. Currently, environmental and health data sets only cohere geographically at a high level, except in some local circumstances. Appropriate statistical methods, such as multilevel regression models for estimating associations between contextual factors and respiratory health outcomes, and path analysis for investigating possible mediators of these associations, need to be applied.

3) Projections of future health impacts need to take into account the key factors that determine the geographic range and incidence of respiratory diseases, including effectiveness of treatment with respect to population, age and sex. 
4) This information can be used to identify indicators for monitoring the respiratory health impacts of climate change in order to modify current and planned programmes for addressing respiratory health issues, thus increasing preparedness for projected climate change impacts.

5) These projections should not be limited to the European region, since changes in other regions, such as desertification leading to increased long-range transport of dust, viruses and other particles, or the spread of respiratory diseases due to warmer temperatures and changing precipitation patterns, could affect the health of European populations.

\section{Augmented basic research on the aetiology and treatment of respiratory diseases}

1) Any disease with a strong seasonal signal, such as respiratory syncytial virus, may be affected by temperature. However, limited research has been conducted as to what role, if any, weather patterns play in their appearance or intensity of transmission.

2) Greater understanding is needed of the biological mechanisms that increase the risk of initiating and exacerbating respiratory diseases both in general and in the context of climate change. Areas that should be investigated include: 1) early programming of and impacts of drugs on thermoregulation, and 2) acclimatisation and adaptation of susceptible populations.

\section{Identification of effective approaches for the prevention and reduction of possible impacts}

1) Research is needed on the clinical efficacy of interventions and treatments in the context of climate change. This should include research on factors, such as nutritional status, that can increase the sensitivity and efficacy of treatments.

2) Evidence is emerging that increasing temperature can amplify the adverse effects of poor air quality. This suggests that advance warnings of adverse conditions should be developed in order to strengthen the capacity of the health system to prepare for the increase in extreme weather events.

3) Methodology should be developed for warning systems and for the evaluation of their effectiveness.

4) There should be greater education of health professionals regarding the respiratory health risks of climate change in order to ensure that patients are adequately informed of how changing weather patterns could affect their health and how medications could affect their sensitivity to heatwaves.

5) Research is needed on the role of housing and indoor climate control systems in respiratory diseases.

\section{Evaluation of the health impacts of policy options for reducing greenhouse gas emissions}

1) It is critical for public health for the ERS to have a strong voice in the evaluation of options for reducing GHG emissions, and to advocate policies on issues including the built environment, transport, energy generation, energy efficiency and agriculture.

2) The health costs and benefits of various policy choices are required in order to inform policy evaluations.

\section{Research focused on particularly vulnerable populations and regions}

1) Children and those with chronic respiratory diseases may be particularly sensitive to the impacts of climate change. Research should focus on identifying those most at risk and implementing effective programmes and activities for reducing their vulnerability. This research should evaluate sensitivity in its broadest sense, including biological, environmental and social factors. This refers to the fact that sensitivity is a complex entity including either susceptibility, i.e. the likelihood of producing a significantly larger-than-average response to climate change effects, or vulnerability, i.e. the likelihood of being unusually severely affected by climate change effects as a result of either susceptibility to the effects of these substances or a greater-than-average exposure.

2) Research should also take into account the fact that climate change may alter the geographical spread of regions at risk.

\section{THE ROLE OF THE EUROPEAN RESPIRATORY SOCIETY IN ADVOCACY}

In view of the complexity and magnitude of the challenge, there is a general misconception that climate change can only be addressed at a national or supranational level. Immediate governmental action is indeed required, but action by healthcare professionals at an individual level may bring about significant incremental effects, not least in protecting the health of their patients.

Respiratory healthcare professionals have a distinguished history of combating major public health concerns, such as air pollution, tuberculosis, tobacco use/exposure and asbestos exposure, and are well placed to play a role in combating climate change and the related adverse effects on health.

As a trusted source, physicians can disseminate information about the health consequences of climate change, the ways to counteract its adverse effects and the co-benefits associated with such actions. Setting an example to their patients, families, communities and organisations by taking steps to reduce the carbon footprint of their homes and practices, and encouraging their organisations to do the same, is a powerful method of engaging others in similar behavioural changes.

Many of the actions that mitigate GHG emissions yield cobenefits for both health and the environment. Energy efficiency saves money on energy bills besides curbing emissions. Reducing automobile dependence promotes physical activity, helps fight obesity and reduces traffic-related injuries. $\mathrm{CO}_{2}$ reductions will improve air quality and subsequently respiratory health.

Consequently, the ERS's approach to advocacy with respect to climate change embraces the following.

1) Policies to promote access to non-polluting and sustainable sources of energy, recognising the need to develop policies that prevent dangerous anthropogenic emissions while addressing the energy needs of disadvantaged populations.

2) Encouragement of the development of new technological options, policy choices and economic instruments for power generation, transport, agriculture and the built environment. This could incorporate the development of a comprehensive 
programme for clean energy which optimises mitigation and allows adaptation to climate change. This needs to be undertaken while appreciating the potential barriers to change, which include vested interests, political inertia, inability to take meaningful action, global inequalities and weak technology transfer mechanisms. Equally importantly, this approach to climate change needs to incorporate intersectoral research, with concerted action being taken at both national and international levels.

3) Education of healthcare professionals and patients on the impact of climate change on respiratory health.

\section{EUROPEAN RESPIRATORY SOCIETY ADVOCATORY ACTIONS WITH REGARD TO CLIMATE-CHANGE- RELATED IMPACTS ON RESPIRATORY AND LUNG HEALTH}

Although regulatory changes to improve air quality are required, the maintenance of respiratory health also largely rests upon changes at a societal level. The European Union (EU) needs more stringent standards for limiting emissions from industry and vehicles, as well as more effective enforcement. Conversely, lifestyle changes centred on reducing energy consumption, e.g. the use of vehicles, are also required. The proposed advocatory actions can be summarised within the two main themes of adaptation and mitigation.

\section{Advocacy at the European level}

1) Ensuring that the respiratory health effects of climate change are considered in all discussions and recommended actions at EU level through the society and supporting the efforts of public interest organisations, such as the Health and Environment Alliance (HEAL) [57].

2) Emphasis of the links between emissions climate change and indoor and outdoor air quality and supporting ongoing review of the current outdoor air quality standards.

3) Identification of areas of research need in both health effect assessment and policy and pressing for calls to support these.

4) Supporting policies that introduce cost-effective measures for reducing emissions that contribute to climate change.

5) Contributing to implementing the World Health Assembly resolution on Climate Change and Health (WHA 61.19, 2008).

\section{Advocacy for practising respiratory healthcare professionals}

1) Encouragement of local public health authorities to develop early warning schemes similar to those already existing for smog, ground-level ozone, airborne allergens and heatwaves, all of which are known to adversely affect individuals with chronic lung disease (adaptation).

2) Promotion of registration of healthcare institutions with the EU's Eco-Management and Audit Scheme (EMAS) or equivalent body (mitigation).

3) Supporting policy changes that could reduce emissions that contribute to climate change.

\section{Advocatory steps of the European Respiratory Society}

1) Dissemination of knowledge of best practice in tackling the effects of extreme weather events on respiratory health (adaptation).

2) Establishment of a set of sustainability criteria for adding to existing metrics when choosing meeting venues and convention centres (mitigation) [58].

3) Continued development of the ERS initiatives in exploring and developing alternative approaches to face-to-face meetings and consideration of the use of carbon offsets [59] where possible (mitigation).

4) Consideration of registration for the EMAS [60]. The EMAS is a voluntary instrument that acknowledges organisations that continuously improve their environmental performance on the basis of environmental reviews and reports (mitigation).

\section{SUPPORT STATEMENT}

M. Medina-Ramón received funding from the Spanish Ministry of Science and Innovation (Madrid, Spain) through the Programme Juan de la Cierva (JCI-2007-47-767). R. Dey and M. Windt are members of the American Thoracic Society Environmental Health Policy Committee and P.J. Helms is the European Respiratory Society Secretary for EU Affairs.

\section{STATEMENT OF INTEREST}

None declared.

\section{ACKNOWLEDGEMENTS}

The affiliations of the present authors are as follows. J.G. Ayres: Institute of Occupational \& Environmental Medicine, University of Birmingham, Birmingham; and P.J. Helms: Dept of Child Health, University of Aberdeen, Royal Aberdeen Children's Hospital, Aberdeen (both UK). B. Forsberg: Occupational and Environmental Medicine, Umeå University, Umeå, Sweden. I. Annesi-Maesano: Epidemiology of Allergic and Respiratory Diseases, Mixed Research Unit-S 707, National Institute for Health and Medical Research and University of Pierre and Marie Curie (Paris 06), Paris, France. R. Dey: Dept of Neurobiology and Anatomy, West Virginia University, Morgantown, WV; K.L. Ebi: ESS, LLC, Alexandria, VA; and M. Windt: Center for Health Enhancement, University of New Hampshire, Durham, NH, and Center for Asthma Allergy and Respiratory Disease, North Hampton, NH (all USA). M. Medina-Ramón: Centre for Research in Environmental Epidemiology, Municipal Institute of Medical Research, Centro de Investigación Biomédica en Red de Epidemiología y Salud Pública, Barcelona, Spain. F. Forastiere: Dept of Epidemiology, Rome E Health Authority, Rome, Italy.

The authors would like to acknowledge the work and support of B. Menne during composition of this position statement.

The present report resulted from a workshop organised by the Environment and Health Committee of the European Respiratory Society (ERS). The authors thank N. Muzio (ERS, Brussels, Belgium) for organising the workshop.

Members of the Environment and Health Committee: I. AnnesiMaesano (National Institute for Health and Medical Research and University of Pierre and Marie Curie (Paris 06)), J. Ayres (University of Birmingham), B. Brunekreef (University of Utrecht, Utrecht, the Netherlands), F. Forastiere (chair; Rome E Health Authority), B. Forsberg (Umeå University), P. Helms (University of Aberdeen, Royal Aberdeen Children's Hospital), N. Kuenzli (University of Basle, Basle, 
Switzerland), J. Pekkanen (National Public Health Institute, Helsinki, Finland), and T. Sigsgaard (University of Aarhus, Aarhus, Denmark). Workshop attendees: R. Anderson (University of London, London, UK), I. Annesi-Maesano (National Institute for Health and Medical Research and University of Pierre and Marie Curie (Paris 06)), J. Ayres (University of Birmingham), A. Bartonova (Norwegian Institute for Air Research, Kjeller, Norway), R. Bertollini (World Health Organization (WHO), Rome Office, Geneva, Switzerland), L. Braback (Sundsvall Hospital, Sundsvall, Sweden), B. Brunekreef (University of Utrecht), K-H. Carlsen (Rikshospitalet, Oslo, Norway), G. D'Amato (University of Naples, Naples, Italy), R. Dey (West Virginia University), J. Douwes (Massey University, Wellington, New Zealand), K. Ebi (ESS, LCC, Alexandria, VA, USA), E. Egaas (National Veterinary Institute, Oslo, Norway), J-L. Eiselé (ERS, Lausanne, Switzerland), G. Ewart (American Thoracic Society, Washington, DC, USA), C. FarrarHockley (Health and Environment Alliance, Brussels, Belgium), F. Forastiere (Rome E Health Authority), B. Forsberg (Umeå University), T.S. Halstensen (University of Oslo, Oslo, Norway), H.C. Hansson (University of Stockholm, Stockholm, Sweden), P. Helms (University of Aberdeen, Royal Aberdeen Children's Hospital), A-K. Hurtig (Umeå University), V. Karloukovska (Health and Environment Alliance), K. Katsouyanni (University of Athens Medical School, Athens, Greece), S. Kovats (London School of Hygiene and Tropical Medicine, London, UK), M. Krayer von Krauss (WHO, Rome), M. Maayor (ERS, Lausanne), D. Mannisero (European Centre for Disease Prevention and Control, Stockholm, Sweden), W. Martin (National Institute for Environmental Health Science, Research Triangle Park, NC, USA), R. Maynard (Health Protection Agency, Chilton, UK), M. Medina-Ramón (Centro de Investigación Biomédica en Red de Epidemiología y Salud Pública, Barcelona, Spain), B. Menne (WHO, Rome), P. Michelozzi (Dept of Epidemiology, Rome E Health Authority), B. Nemery (University of Leuven, Leuven, Belgium), J. Pekkanen (National Public Health Institute, Helsinki, Finland), C. Perucci (Dept of Epidemiology, Rome E Health Authority), J. Rocklov (Umeå University), T. Sigsgaard (University of Aarhus), R. Stott (Medact, London, UK), J. Versnel (European Federation of Allergic and Airway Diseases Patients Association, Brussels, Belgium), G. Viegi (Consiglio Nazionale delle Ricerche, Pisa, Italy), P. Wilkinson (London School of Hygiene and Tropical Medicine), M. Windt (University of New Hampshire), and D. Zmirou (INSERM, Vandoeuvre-lès-Nancy, France).

\section{REFERENCES}

1 World Meteorological Organization, United Nations Environment Programme. Intergovernmental Panel on Climate Change. www. ipcc.ch/ Date last accessed: 26 May 2009.

2 Matthies F, Bickler G, Cardeñosa Marín N, et al., eds. Heat-Health Action Plans. Guidance. Copenhagen, World Health Organization Regional Office for Europe, 2008.

3 Wilkinson P, Smith KR, Beevers S, et al. Energy, energy efficiency, and the built environment. Lancet 2007; 370: 1175-1187.

4 Godlee F. Climate change: our new responsibility. BMJ 2008; 336: a529.

5 Rom WN, Pinkerton KE, Martin WJ, et al. Global warming: a challenge to all American Thoracic Society members. Am J Respir Crit Care Med 2007; 177: 1053-1054.

6 Sardon JP. The 2003 heat wave. Euro Surveill 2007; 12: 694

7 Haines A, Smith KR, Anderson D, et al. Policies for accelerating access to clean energy, improving health, advancing development, and mitigating climate change. Lancet 2007; 370: 1264-1281.

8 Stafoggia M, Forastiere F, Agostini D, et al. Vulnerability to heatrelated mortality: a multicity, population-based, case-crossover analysis. Epidemiology 2006; 17: 315-323.

9 Baccini M, Biggeri A, Accetta G, et al. Heat effects on mortality in 15 European cities. Epidemiology 2008; 19: 711-719.
10 Stafoggia M, Forastiere F, Agostini D, et al. Factors affecting inhospital heat-related mortality: a multi-city case-crossover analysis. J Epidemiol Community Health 2008; 62: 209-215.

11 Michelozzi P, Accetta G, De Sario M, et al. High temperature and hospitalizations for cardiovascular and respiratory causes in 12 European cities. Am J Respir Crit Care Med 2009; 179: 383-389.

12 Patz JA, Engelberg D, Last J. The effects of changing weather on public health. Annu Rev Public Health 2000; 21: 271-307.

13 Jacob DJ, Winner DA. Effect of climate change on air quality. Atmos Environ 2009; 43: 51-63.

14 Ebi KL, McGregor G. Climate change, tropospheric ozone and particulate matter, and health impacts. Environ Health Perspect 2008; 116: 1449-1455.

15 Uysal N, Schapira RM. Effects of ozone on lung function and lung diseases. Curr Opin Pulm Med 2003; 9: 144-150.

16 Mudway IS, Kelly FJ. Ozone and the lung: a sensitive issue. Mol Aspects Med 2000; 21: 1-48.

17 Spix C, Anderson HR, Schwartz J, et al. Short-term effects of air pollution on hospital admissions of respiratory diseases in Europe: a quantitative summary of APHEA study results. Air Pollution and Health: a European Approach. Arch Environ Health 1998; 53: 54-64.

18 Medina-Ramón M, Zanobetti A, Schwartz J. The effect of ozone and PM10 on hospital admissions for pneumonia and chronic obstructive pulmonary disease: a national multicity study. $A m \mathrm{~J}$ Epidemiol 2006; 163: 579-588.

19 Gryparis A, Forsberg B, Katsouyanni K, et al. Acute effects of ozone on mortality from the "Air Pollution and Health: a European Approach" project. Am J Respir Crit Care Med 2004; 170: 1080-1087.

20 Bell ML, McDermott A, Zeger SL, et al. Ozone and short-term mortality in 95 US urban communities, 1987-2000. JAMA 2004; 292: 2372-2378.

21 Kovats S, ed. Health Effects of Climate Change in the UK 2008. An Update of the Department of Health Report 2001/2002. London, Department of Health, 2008.

22 Trenberth KE, Jones PD, Ambenje P, et al. 2007. Observations: surface and atmospheric climate change. In: Solomon S, Qin D, Manning M, et al., eds. Climate Change 2007: the Physical Science Basis. Contribution of Working Group I to the Fourth Assessment Report of the Intergovernmental Panel on Climate Change. Cambridge, Cambridge University Press, 2007; pp. 235-336.

23 Salvi S. Health effects of ambient air pollution in children. Paediatr Respir Rev 2007; 8: 275-280.

24 Laden F, Schwartz J, Speizer FE, et al. Reduction in fine particulate air pollution and mortality. Extended follow-up of the Harvard Six Cities study. Am J Respir Crit Care Med 2006; 173: 667-672.

25 Pope CA 3rd, Burnett RT, Thun MJ, et al. Lung cancer, cardiopulmonary mortality, and long-term exposure to fine particulate air pollution. JAMA 2002; 287: 1132-1141.

26 Abbey DE, Nishino N, McDonnell WF, et al. Long-term inhalable particles and other air pollutants related to mortality in nonsmokers. Am J Respir Crit Care Med 1999; 159: 373-382.

27 Pope CA 3rd, Dockery DW. Health effects of fine particulate air pollution: lines that connect. J Air Waste Manag Assoc 2006; 56: 709-742.

28 Atkinson RW, Anderson HR, Sunyer J, et al. Acute effects of particulate air pollution on respiratory admissions. Results from APHEA 2 project. Am J Respir Crit Care Med 2001; 164: 1860-1866.

29 Analitis A, Katsouyanni K, Dimakopoulou K, et al. Short-term effects of ambient particles on cardiovascular and respiratory mortality. Epidemiology 2006; 17: 230-233.

30 Levy JI, Chemerynski SM, Sarnat JA. Ozone exposure and mortality: an empiric Bayes metaregression analysis. Epidemiology 2005; 16: 458-468.

31 Ren C, Williams GM, Mengersen K, et al. Does temperature modify short-term effects of ozone on total mortality in 60 large 
eastern US communities? An assessment using the NMMAPS data. Environ Int 2008; 34: 451-458.

32 Sartor F, Snacken R, Demuth C, et al. Temperature, ambient ozone levels, and mortality during summer 1994, in Belgium. Environ Res 1995; 70: 105-113.

33 Stafoggia M, Schwartz J, Forastiere F, et al. Does temperature modify the association between air pollution and mortality? A multicity case-crossover analysis in Italy. Am J Epidemiol 2008; 167: 1476-1485.

34 Ren C, Williams GM, Tong S. Does particulate matter modify the association between temperature and cardiorespiratory diseases? Environ Health Perspect 2006; 114: 1690-1696.

35 Valavanidis A, Loridas S, Vlahogianni T, et al. Influence of ozone on traffic-related particulate matter on the generation of hydroxyl radicals through a heterogeneous synergistic effect. J Hazard Mater 2009; 162: 886-892.

36 Gunnbjornsdottir MI, Franklin KA, Norback D, et al. Prevalence and incidence of respiratory symptoms in relation to indoor dampness: the RHINE study. Thorax 2006; 61: 221-225.

37 Fisk WJ, Lei-Gomez Q, Mendell MJ. Meta-analyses of the associations of respiratory health effects with dampness and mold in homes. Indoor Air 2007; 17: 284-296.

38 Jacob B, Ritz B, Gehring U, et al. Indoor exposure to molds and allergic sensitization. Environ Health Perspect. 2002; 110: 647-653.

39 Mudarri D, Fisk WJ. Public health and economic impact of dampness and mold. Indoor Air 2007; 17: 226-235.

40 Jaakkola MS, Laitinen S, Piipari R, et al. Immunoglobulin G antibodies against indoor dampness-related microbes and adultonset asthma: a population-based incident case-control study. Clin Exper Immunol 2002; 129: 107-112.

41 Peat JK, Tovey E, Toelle BG, et al. House dust mite allergens. A major risk factor for childhood asthma in Australia. Am J Respir Crit Care Med 1996; 153: 141-146.

42 Howden-Chapman P, Matheson A, Crane J, et al. Effect of insulating existing houses on health inequality: cluster randomised study in the community. BMJ 2007; 334: 460-464.

43 Osman LM, Ayres JG, Garden C, et al. Home warmth and health status of COPD patients 1. Eur J Public Health 2008; 18: 399-405.

44 D'Amato G, Cecchi L, Bonini S, et al. Allergenic pollen and pollen allergy in Europe. Allergy 2007; 62: 976-990.

45 Holz O, Mucke M, Paasch K, et al. Repeated ozone exposures enhance bronchial allergen responses in subjects with rhinitis or asthma. Clin Exper Allergy 2002; 32: 681-689.

46 Packe GE, Ayres JG. Asthma outbreak during a thunderstorm. Lancet 1985; ii: 199-203.
47 Higham J, Venables K, Kupek E, et al. Asthma and thunderstorms: description of an epidemic in general practice in Britain using data from a doctors' deputising service in the UK. I Epidemiol Community Health 1997; 51: 233-238.

48 Bellomo R, Gigliotti P, Treloar A, et al. Two consecutive thunderstorm associated epidemics of asthma in the city of Melbourne. The possible role of rye grass pollen. Med J Australia 1992; 156: 834-837.

49 D'Amato G, Cecchi L, Liccardi G. Thunderstorm-related asthma: not only grass pollen and spores. J Allergy Clin Immunol 2008; 121 537-538.

50 D'Amato G, Liccardi G, Frenguelli G. Thunderstorm-associated asthma in pollinosis patients. Allergy 2007; 62: 11-16.

51 Health and Environment Linkages Initiative. Indoor Air Pollution and Household Energy. www.who.int/heli/risks/indoorair/ indoorair/en/ Date last updated: 2009. Date last accessed: June 2, 2009.

52 Levy H II, Shindell D, Gilliland A, eds. Climate Projections Based on Emissions Scenarios for Long-Lived and Short-Lived Radiatively Active Gases and Aerosols. A Report by the U.S. Climate Change Science Program and the Subcommittee on Global Change Research. Washington, Department of Commerce, National Oceanic and Atmospheric Administration's National Climatic Data Center, 2008.

53 Baker M, Das D, Venugopal K, et al. Tuberculosis associated with household crowding in a developed country. I Epidemiol Community Health 2008; 62: 715-721.

54 Ayres JG. Seasonal pattern of acute bronchitis in general practice in the United Kingdom. Thorax 1986; 41: 106-110.

55 Rezza G, Nicoletti L, Angelini R, et al. Infection with chikungunya virus in Italy: an outbreak in a temperate region. Lancet 2007; 370: 1840-1846.

56 Gilbert M, Slingenbergh J, Xiao X. Climate change and avian influenza. Rev Sci Tech 2008; 27: 459-466.

57 Health and Environment Alliance. Climate Change. www.envhealth.org/r/93 Date last accessed: 26 May 2009.

58 Baller M, Blickwedel P, Dubrikow K-M, et al. Guidelines for the Environmentally Sound Organisation of Events. Federal Environmental Agency, 2006.

59 Kollmuss A, Zink H, Polycarp C. Making Sense of the Voluntary Carbon Market. A Comparison of Carbon Offset Standards. World Wildlife Fund Germany, 2008.

60 European Commission. EMAS - The European Eco-Management and Audit Scheme. http://ec.europa.eu/environment/emas/ about/summary_en.htm Date last updated: April 20, 2009. Date last accessed: June 2, 2009. 